\section{Program evaluation as an important practical implication of Van Howe and Storm's paper}

\author{
Mpho Selemogo \\ Public Health Medicine trainee, School \\ of Medicine, University of Botswana
}

Van Howe and Storm's paper is commendable for asking valid questions regarding the scientific evidence upon which circumcision as an HIV prevention strategy is based. ${ }^{1}$ The paper however gives no real practical suggestions as to what the way forward should be regarding the already rolled out circumcision programs in Africa.

Its position that the current circumcision programs amount to a waste of resources on something less effective, more expensive, and more invasive has the potential of bringing despair and discouragement to workers in the already rolled-out circumcision programs such as one in Botswana. Except for suggesting that the new focus should be on iatrogenic sources of HIV transmission and secondary prevention, the paper unfortunately offers no real practical suggestions to public health workers already implementing national circumcision programs, most of which are still in their infancy. This contribution seeks to highlight the importance of rigorous program evaluation as a crit- ical practical implication of the paper and a way forward for such programs.

Program evaluation of the circumcision programs to assess their impact holds the potential of ultimately answering the question of whether circumcision programs are a waste of resources or not. Van Howe and Storm themselves admit that it is unknown how the results of the RCTs, questionable as they may be, will translate to the real world. Before such rigorous evaluation of the existing programs can be done, it will be a missed opportunity to just label the programs a waste based on speculation rather than on concrete evidence arising from their evaluation.

Program evaluation also holds the potential of shedding light into whether behavioral compensation in those who are circumcised will be a reality or not. While Van Howe and Storm boldly proclaim that risk compensation will accompany the circumcision solution in Africa through lowering condom use, they are themselves not completely certain if it will indeed result in lower condom use. They cannot be certain about the alleged risk compensation as by their own admission they do not know how the results of the RCTs will translate to the real world. Impact evaluation of the circumcision programs could again clarify whether circumcision will in real life indeed reduce condom use. For Africa, the questionable nature of the evidence for circumcision as suggested by Van Howe and Storm problably suggests that program evaluation can no longer be taken as a lluxury that it has tended to be perceived to be, but rather as a tool for establishing the truth
Correspondence: Mpho Selemogo, Public Health Medicine trainee, School of Medicine, University of Botswana, 4775 Notwane Rd. Gaborone, Botswana. Tel. +267.3550000 Fax: +267.3956591 . E-mail: mphogift@yahoo.com

Key words: Circumcision, program evaluation.

Conflict of interest: the authors report no conflicts of interest.

Received for publication: 24 March 2011. Accepted for publication: 23 June 2011.

This work is licensed under a Creative Commons Attribution NonCommercial 3.0 License (CC BYNC 3.0).

(C) Copyright M. Selemogo, 2011

Licensee PAGEPress, Italy

Journal of Public Health in Africa 2011; 2:e32 doi:10.4081/jphia.2011.e32

about the real impact of circumcision on the ground.

\section{Reference}

1. Van Howe RS, Storms MR. How the circumcision solution in Africa will increase HIV infections. Journal of Public Health in Africa 2011;2:e4. 